OPEN ACCESS

Edited by:

Gagan Deep Sharma, Guru Gobind Singh Indraprastha University, India

Reviewed by:

Pingfan Xia,

National University of Singapore,

Singapore

Huaping Sun,

Jiangsu University, China

${ }^{*}$ Correspondence:

Xin Zhao

zhaoshin1993@hotmail.com

Specialty section:

This article was submitted to

Environmental Economics and

Management,

a section of the journal

Frontiers in Environmental Science

Received: 21 January 2022

Accepted: 11 February 2022

Published: 02 March 2022

Citation:

Cai X, Wang W, Rao A, Rahim S and

Zhao X (2022) Regional Sustainable Development and Spatial Effects From the Perspective of Renewable Energy.

Front. Environ. Sci. 10:859523.

doi: 10.3389/fenvs.2022.859523

\section{Regional Sustainable Development and Spatial Effects From the Perspective of Renewable Energy}

\author{
Xiaowei Cai ${ }^{1}$, Wenjing Wang ${ }^{1}$, Amar Rao ${ }^{2}$, Syed Rahim ${ }^{3}$ and Xin Zhao ${ }^{1 *}$ \\ ${ }^{1}$ School of Statistics and Applied Mathematics, Anhui University of Finance and Economics, Bengbu, China, ${ }^{2}$ School of Business \\ Management, Shoolini University, Solan, India, ${ }^{3}$ Pakistan Institute of Development Economics, Islamabad, Pakistan
}

Green development is crucial for promoting high-quality and sustainable economic and social development. In China, green development is key to achieving the national goals of building a beautiful China and rejuvenating the nation. In this study, we employed a slacksbased measure data envelopment analysis method to calculate the green development efficiency value of panel data from Anhui Province, China, from 2005 to 2020. Moreover, the Malmquist Index was used to dynamically analyze the green total-factor productivity and decomposition index of 16 cities in Anhui Province. Exploratory spatial data analysis was used to measure the spatial relationship of the green development efficiency value for each province in Anhui Province. Then, we established the spatial lag model according to the spatial correlation and perform a comprehensive analysis of the impact and spillover effects. The results show that: The overall green development efficiency of all urban areas in Anhui Province showed a fluctuating trend, but most cities exhibiting medium of higher green development efficiency.Various cities exhibited spatial aggregation, with high, high, and low values of green development efficiency. The industrial structure, digital economy development, and the urbanization level showed relatively significant positive correlations with the regional economic development level, whereas the energy structure and level of opening up showed a significant negative correlation.The influence of environment management and scientific and technological development was not significant.the industrial structure, and the urbanization rate showed positive effects on local green development but negative spillover effects on surrounding areas, whereas the energy structure, relative economic development, and level of opening up produced positive spillover effects.

Keywords: sustainable development, spillover effect, influencing factor, spatial correlation, renewable energy

\section{INTRODUCTION}

Since the 18th National Congress of the Chinese Communist Party, China has been exploring ways to combine economic development with environmental protection in ecological progress, focusing on green development as a core principle of ecological progress. The concept of green development includes the new concept of innovative, coordinated, green, open, and shared development, and is the key premise of sustainable development (Shahzad et al., 2021). In 2005, the general secretary proposed the concept of "green mountains and clear water are equal to mountains of gold and silver," which states that creating a green environment requires adhering to the concepts of gradual 
ecological and green development, constructing a new scientific development engine, promoting the development of a green economy, and transforming ecological benefits into economic benefits (Song et al., 2022). Thus, green and sustainable development requires the effective integration of economic development with the ecological environment. Green development is also key to achieving ecological civilization and is a prerequisite for economic and social development. As China enters the 14th stage of its Five-Year Plan in 2021, there is a broad consensus to promote a new and green style of development (Xia et al., 2022).

Previous research on green development mainly includes the following two aspects: measurement of the green development efficiency and factors influencing the efficiency of green development. Regarding the measurement of the green development efficiency, Reinhard et al. (2000) used input and output factors to effectively evaluate and measure technological and environmental efficiency, Lozano and Gutiérrez, (2011) used SBM analyses the efficiency of 39 Spanish Airports, Guo et al. (2017) established a model redistribution scheme from the perspective of pollutants that considered multiple factors through multi-criteria analysis and input-output analysis, evaluated the spillover effect, and conducted Monte Carlo simulations and sensitivity analysis. Feng et al. (2017) used DEA to evaluate and compare the green development performance index of 165 counties in 41 regions of China, and analyzed the influencing by using Tobit censored regression model. Another study comprehensively analyzed the development trend, correlation, factor change, and heterogeneity of 20 urban agglomerations in China divided into four development zones (Huang and Lin, 2017; Sun et al., 2021a; Shahzad et al., 2022). Furthermore, Zhou et al. (2020) used the slacks-based measure (SBM)-Malmquist Index, Thayer index, and spatial Markov chain to comprehensively analyze the spatio-temporal differences and dynamic characteristics of the green development level, as well as the natural, human, and social factors using Tobit regression. Based on fuzziness and uncertainty, Li et al. (2020) used an evaluation method based on the S-type cloud model to evaluate the green development level of 13 cities in China from five environmental perspectives. Moreover, Finally, Tian and Liu (2021) employed the superefficiency SBM-DEA model and the global Malmquist Index decomposition method to reveal a relatively high level of regional green development efficiency in Shaanxi Province, China.

To evaluate the factors influencing the efficiency of green development, Acemoglu et al. (2012), the endogenous and directional technological change factors are introduced into the growth model with environmental impact, and the spillover effects related to regional environment are solved by using functions. Burnett et al. (2013) used the energy demand model to collect panel data to conduct in-depth studies on the relationship between carbon dioxide emissions and economic activities, and explained the spatial dependence between states to conduct relevant studies. Moreover, Chen (2016) employed SBMUndesirable and Malmquist Exponential models to measure the evolution and variation of environmental efficiency in China, and used spatial metrics to explore the effects of environmental regulation, urbanization, industrial structure, and technological innovation on regional green development. Other research has used the super-SBM model and spatial Durbin model to study the evolution of China's green development from the perspective of spatial correlation and heterogeneity, while comprehensively considering spillover effects (Che et al., 2018; Sun et al., 2021b; Zhao et al., 2022). Li et al. (2019) used TopSIS and obstacle degree analysis to study spatial and temporal changes in the green development level and limiting factors in Shaanxi Province. Yuan et al. (2020) analyzed the impact of finance on regional green development, as well as spatial threshold and spillover effects, for 272 prefecture-level cities using spatial Durbin and panel threshold regression model. Additionally, Liu et al. (2019) analyzed differences in green development by k-means clustering, and measured the efficiency of green innovation using improved SMB-DEA, whereas $\mathrm{Wu}$ et al. (2020) employed panel data and the DEA model to measure the level of green development, introducing the super-PEBM model (based on Pearson's correlation coefficient) to study the regional differences and other problems. Furthermore, MerinoSaum et al. (2020) Used the electrical definition as a concept to study the green development of the region, the potential tradeoffs and synergies between the economic and environmental dimensions are studied. Wang and $\mathrm{Li}$, (2020) considered the impact of environmental welfare efficiency and industry on green development for 30 provinces in China based on the network loose measure. Peng (2020) used urban data to analyze the impact of regional strategic interaction and green productivity, as well as different spatial matrices to analyze the corresponding effects of the green development index. Subsequently, Liu et al. (2020) used kernel density estimation and panel data model to perform a corresponding evaluation and difference analysis on green development of agriculture. According to the SLX model, Hille et al. (2021) used the dynamic panel Han-Phillips Estimator to estimate the spillover effect of neighboring provinces. Finally, Si et al. (2021) used the SBM-DEA model of unexpected output, convergence coefficient, coordination matrix, GIS, and panel Tobit model to study the efficiency of green development.

Thus, previous literature has been characterized by diverse research methods, varied aims, and abundant results. However, there are several areas requiring further study. 1) most of scholars studied for large areas, such as the Yellow River basin and the Yangtze river basin, its assessment and analysis on green development efficiency value in 2) the research methods for static analysis or dynamic analysis of a single method, namely the research methods are unilateral 3) lack of spillover effects for the influencing factors of comprehensive analysis, To some extent, it weakens the research on the spillover effects of relevant influencing factors on local and surrounding areas of green development. In this study, we take Anhui Province as the research object and conduct a statistical analysis of the efficiency index of green development based on the super-efficiency SBMDEA model of unexpected output. We then establish the most appropriate spatial econometric model based on exploratory spatial data analysis, and analyze the factors influencing green development and its spillover effects. This research has both 
theoretical and practical significance for understanding regional green development efficiency in China. We use a more comprehensive method to calculate the regional green development level comprehensively and carefully, which has a certain theoretical and practical significance.

\section{MEASUREMENT OF GREEN DEVELOPMENT EFFICIENCY IN ANHUI PROVINCE}

In this study, We selected 16 cities in Anhui province, including Hefei, Wuhu, Bengbu, Huainan, Maanshan, Huaibei, Tongling, Anqing, Huangshan, Fuyang, Suzhou, Chuzhou, Luan, Xuancheng, Chizhou and Bozhou as the research object, collected relevant data, then measured the regional green development efficiency index.

\section{Research Methods}

\section{Super SBM-DEA Model}

DEA is a comprehensive method for multi-input and multioutput evaluation, which can evaluate the relative efficiency evaluation of multiple decision making units (DMUs) with multiple inputs and outputs without quantitative normalization of data. In this study, we used the super-SBM model with unexpected outputs to distinguish and rank the evaluation DMUs. Each city is regarded as a DMU, and the input-output index data of Anhui Province from 2005 to 2020 were selected to measure the comprehensive green development level of each city. The specific model is as follows:

$$
\begin{gathered}
P_{U-s-S B M}: \min \varphi=\frac{1+\frac{1}{m} \sum_{i=1}^{m} \frac{\omega_{i}^{-}}{x_{i 0}}}{1-\frac{1}{s_{1}+s_{2}}\left(\sum_{r=1}^{n_{i}} \frac{\omega_{r}^{+}}{y_{r 0}}+\sum_{u=1}^{2} \frac{\omega_{u}^{+}}{z_{u 0}}\right)} \\
\text { (s.t) } x_{i o} \geq \sum_{j=1, z 0}^{n} \lambda_{j} x_{i j}-\omega_{i}^{-}, i=1, \cdots m \\
y_{r o} \geq \sum_{j=1, \infty o}^{n} \lambda_{j} y_{r j}+\omega_{r}^{+}, i=1, \cdots s_{1} \\
z_{u o} \geq \sum_{j=1, \neq 0}^{n} \lambda_{j} z_{u j}-\omega_{u}^{+}, i=1, \cdots s_{2} \\
\lambda_{j}>0, j=1, \cdots, n, j \neq o, \omega_{i}^{-} \geq 0, \omega_{r}^{+} \geq 0, \omega_{u}^{+} \geq 0
\end{gathered}
$$

where $\mathrm{n}$ is the number of cities, each of which contains $m$ input data, $s_{1}$ is the expected output data, and $s_{2}$ is the undesired output data, $\omega$ represents the corresponding slack variables, $\lambda$ is the weight vector, with $\mathrm{X}, \mathrm{Y}$, and $\mathrm{Z}$ used to represent the inputs, expected outputs, and unexpected production data in a matrix a, and $p$ is the value of efficiency.

\section{Global Malmquist-Luenberger Index}

Super-efficiency DEA provides a static description of the green development level. According to the super-efficiency SBM model, the GBL index can be used to dynamically supplement the above model. This index can dynamically analyze changes in the efficiency values before and after two years, and can be decomposed into the relevant changes in efficiency and technology. The GML index formula is as follows:

$$
M_{g}\left(x^{t+1}, y^{t+1}, x^{t}, y^{t}\right)=\frac{E^{g}\left(x^{t+1}, y^{t+1}\right)}{E^{g}\left(x^{t}, y^{t}\right)}
$$

The GML index can be further decomposed into the product of technical efficiency index (EC) and the technical progress index (TC):

$$
\begin{aligned}
M_{g}\left(x^{t+1}, y^{t+1}, x^{t}, y^{t}\right) & =\frac{E^{g}\left(x^{t+1}, y^{t+1}\right)}{E^{g}\left(x^{t}, y^{t}\right)} \\
& =\frac{E^{t+1}\left(x^{t+1}, y^{t+1}\right)}{E^{t}\left(x^{t}, y^{t}\right)}\left(\frac{E^{g}\left(x^{t+1}, y^{t+1}\right)}{E^{t+1}\left(x^{t+1}, y^{t+1}\right)} \times \frac{E^{t}\left(x^{t}, y^{t}\right)}{E^{g}\left(x^{t}, y^{t}\right)}\right) \\
& =\mathrm{EC} \times \mathrm{TC}
\end{aligned}
$$

where $x^{t}$ and $x^{t+1}$ represent the input vectors of different regions in periods $\mathrm{T}$ and $\mathrm{T}+1$, respectively, and $y^{t} y^{t+1}$ represent the output vectors of regions in periods $\mathrm{T}$ and $\mathrm{T}+1$, respectively. $E^{t}\left(x^{t}, y^{t}\right)$ and $E^{t+1}\left(x^{t+1}, y^{t+1}\right)$ represent the distance functions of production points in periods $\mathrm{T}$ and $\mathrm{T}+1$, respectively, with period $\mathrm{T}$ as the reference point. GML $>1$ indicates that the efficiency value of green development increases, whereas GML $<1$ indicates that the efficiency value decreases.

\section{Data Sources}

Data were mainly collected from the "China Statistical Yearbook," "China Environmental Statistical Yearbook," "Anhui Statistical Yearbook," and the corresponding statistical yearbooks of various prefecture-level cities from 2005 to 2020. We selected relevant data for 16 prefecture-level cities in Anhui Province from 2005 to 2020. Individual data or controls that could not be obtained were supplemented using the means method.

\section{Index Selection}

To study the current situation of green development efficiency in 16 cities of Anhui Province, several factors influencing the regional green development level from 2005 to 2020 were selected, as shown in Table 1. According to the ecological concept of green development, we selected the corresponding input-output indexes that affect the level of regional green economic development, then introduced the undesirable outputs.

\section{Empirical Analysis}

\section{Measurement of Regional Green Development Efficiency}

First, we collected the relevant input-output indicators for the 16 prefecture-level cities in Anhui Province, and used MaxDEA software to calculate the corresponding green development efficiency values from 2005 to 2020 using the method of constant return to scale. The calculation results are shown in Table 2.

A green development efficiency value of less than one, 0.6-1.0, and greater than one is characterized as low, medium, and high, respectively (Tian and Liu, 2021). The green development level of all cities in Anhui Province is medium or higher, and the overall 
TABLE 1 | Indexes used to evaluate green development efficiency in this study.

\begin{tabular}{|c|c|c|c|}
\hline \multicolumn{2}{|l|}{ Index selection } & Indicator variables & \multirow{2}{*}{$\begin{array}{l}\text { Unit } \\
\text { thouTsands of people } \\
\text { individuals } \\
10,000 \text { yuan } \\
\text { billion kilowatt-hours } \\
\text { yuan }\end{array}$} \\
\hline Inputs & $\begin{array}{l}\text { Labor input } \\
\text { Enterprise quantity input } \\
\text { Science and technology input } \\
\text { Energy input } \\
\text { Monetary supply }\end{array}$ & $\begin{array}{l}\text { Number of employed persons } \\
\text { Number of industrial enterprises above a designated size } \\
\text { Science and technology expenditure in the general public budget } \\
\text { Electricity consumption for the whole society } \\
\text { Balance of loans of financial institutions at the end of the year }\end{array}$ & \\
\hline Expected outputs & $\begin{array}{l}\text { Economic benefits } \\
\text { Social benefits } \\
\text { Industrial profits } \\
\text { Ecological benefits } \\
\text { - }\end{array}$ & $\begin{array}{l}\text { Municipal GDP } \\
\text { Per capita disposable income of urban residents } \\
\text { Industrial added value } \\
\text { Afforestation coverage rate of built-up areas } \\
\text { Green areas }\end{array}$ & $\begin{array}{l}100 \text { million yuan } \\
\text { yuan } \\
100 \text { million yuan } \\
\% \\
\text { hectares }\end{array}$ \\
\hline Undesirable outputs & Environmental pollution & $\begin{array}{l}\text { Total industrial wastewater discharge } \\
\text { Total industrial exhaust emissions } \\
\text { Production of industrial waste solids }\end{array}$ & $\begin{array}{l}10,000 \text { tons } \\
100 \text { million standard cubic meters } \\
10,000 \text { tons }\end{array}$ \\
\hline
\end{tabular}

TABLE 2 | Green development efficiency level for all cities in Anhui Province.

\begin{tabular}{|c|c|c|c|c|c|c|c|c|c|c|c|c|c|c|c|c|}
\hline Cities & 2005 & 2006 & 2007 & 2008 & 2009 & 2010 & 2011 & 2012 & 2013 & 2014 & 2015 & 2016 & 2017 & 2018 & 2019 & 2020 \\
\hline Hefei & 1.03 & 1.03 & 1.16 & 1.25 & 1.29 & 1.21 & 1.07 & 1.08 & 1.10 & 1.13 & 1.17 & 1.15 & 1.16 & 1.13 & 1.12 & 1.12 \\
\hline Wuhu & 1.53 & 1.20 & 1.10 & 1.15 & 1.17 & 1.18 & 1.13 & 1.15 & 1.17 & 1.17 & 1.16 & 1.11 & 1.13 & 1.12 & 1.11 & 1.11 \\
\hline Bengbu & 1.03 & 1.00 & 1.07 & 1.06 & 1.01 & 1.03 & 1.03 & 1.01 & 1.01 & 1.04 & 1.07 & 1.04 & 1.09 & 1.10 & 1.10 & 1.08 \\
\hline Huainan & 1.02 & 0.80 & 1.02 & 1.03 & 1.01 & 1.01 & 0.61 & 0.70 & 0.61 & 1.00 & 1.02 & 1.01 & 1.01 & 0.74 & 0.69 & 0.77 \\
\hline Maanshan & 1.16 & 1.07 & 1.07 & 1.09 & 1.09 & 1.04 & 1.03 & 1.04 & 1.02 & 1.05 & 1.07 & 1.06 & 1.06 & 1.05 & 1.12 & 1.11 \\
\hline Huaibei & 1.07 & 0.80 & 1.25 & 1.21 & 1.14 & 1.18 & 1.11 & 1.19 & 1.31 & 1.24 & 1.33 & 1.49 & 1.23 & 1.58 & 1.15 & 1.30 \\
\hline Tongling & 1.08 & 1.00 & 1.25 & 1.29 & 1.30 & 1.39 & 1.39 & 1.42 & 1.46 & 1.46 & 1.16 & 1.10 & 1.13 & 1.12 & 1.10 & 1.10 \\
\hline Anqing & 1.37 & 1.24 & 1.02 & 1.05 & 1.05 & 1.12 & 1.12 & 1.16 & 1.12 & 1.12 & 1.08 & 1.11 & 1.09 & 1.10 & 1.11 & 1.08 \\
\hline Huangshan & 1.55 & 1.86 & 1.17 & 1.25 & 1.42 & 1.24 & 1.12 & 1.08 & 1.06 & 1.13 & 1.26 & 1.09 & 1.15 & 1.12 & 1.16 & 1.14 \\
\hline Chuzhou & 1.07 & 1.04 & 1.04 & 1.03 & 1.06 & 1.07 & 1.08 & 1.04 & 1.06 & 1.04 & 1.11 & 1.04 & 1.03 & 1.03 & 1.15 & 1.11 \\
\hline Fuyang & 0.90 & 1.10 & 1.04 & 1.06 & 1.02 & 1.07 & 1.02 & 1.00 & 1.02 & 1.09 & 1.07 & 0.66 & 1.02 & 1.08 & 1.07 & 1.05 \\
\hline Suzhou & 1.02 & 1.04 & 1.01 & 1.00 & 0.61 & 1.00 & 1.02 & 1.05 & 1.04 & 1.03 & 1.10 & 1.05 & 1.07 & 1.04 & 1.09 & 1.08 \\
\hline Luan & 0.90 & 1.02 & 0.71 & 1.01 & 0.63 & 1.09 & 1.02 & 0.67 & 1.00 & 1.00 & 1.04 & 1.13 & 1.07 & 1.13 & 1.13 & 1.12 \\
\hline Bozhou & 0.80 & 0.90 & 1.29 & 0.90 & 1.48 & 1.23 & 1.24 & 1.31 & 1.21 & 1.21 & 1.08 & 1.14 & 1.03 & 1.04 & 1.04 & 1.0 \\
\hline Chizhou & 1.06 & 1.15 & 1.19 & 1.16 & 1.14 & 1.08 & 1.13 & 1.13 & 1.15 & 1.13 & 1.21 & 1.24 & 1.39 & 1.26 & 1.29 & 1.2 \\
\hline Xuancheng & 1.15 & 1.33 & 1.28 & 1.14 & 1.10 & 1.01 & 1.04 & 1.07 & 1.07 & 0.67 & 1.04 & 1.09 & 1.09 & 1.07 & 1.20 & 1.30 \\
\hline The average & 1.11 & 1.10 & 1.10 & 1.11 & 1.10 & 1.12 & 1.07 & 1.07 & 1.09 & 1.09 & 1.12 & 1.09 & 1.11 & 1.11 & 1.10 & 1.1 \\
\hline
\end{tabular}

\section{A}

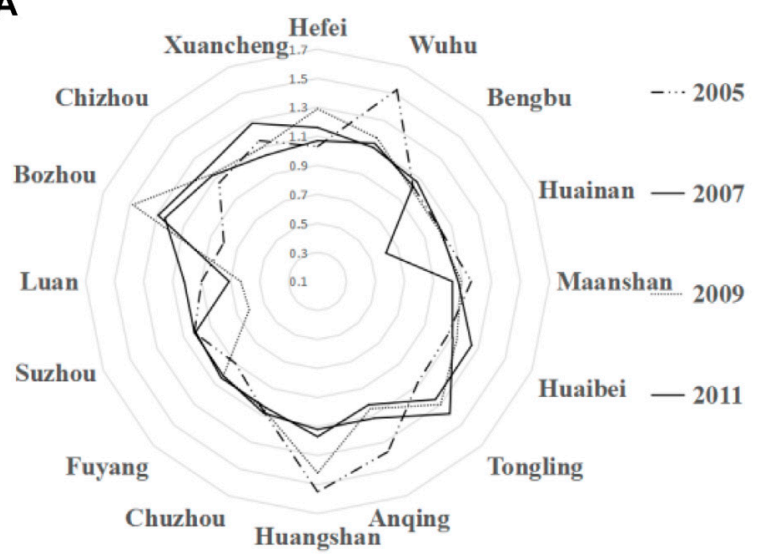

B

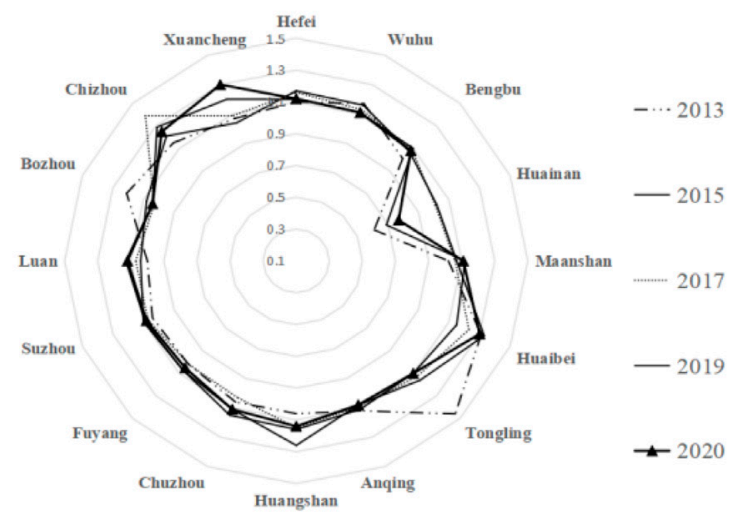

FIGURE 1 | Radar chart of green development efficiency of various cities in Anhui Province from (A) 2005 to 2011 and (B) 2013 to 2020. 
TABLE 3 | Differentiated values of green development levels for selected years in the study period.

\begin{tabular}{|c|c|c|c|c|c|c|}
\hline Efficiency level & 2005 & 2010 & 2015 & 2016 & 2019 & 2020 \\
\hline Low quality green development level & $(0.80,0.90)$ & $(1.00,1.04)$ & $(1.02,1.04)$ & $(0,0.66)$ & $(0,0.69)$ & $(0,0.67)$ \\
\hline Medium quality green development level & $(0.90,1.08)$ & $(1.04,1.12)$ & $(1.04,1.11)$ & $(0.66,1.06)$ & $(0.69,1.13)$ & $(0.67,1.08)$ \\
\hline Good quality green development level & $(1.08,1.16)$ & $(1.12,1.24)$ & $(1.11,1.21)$ & $(1.06,1.24)$ & $(1.13,1.20)$ & $(1.08,1.14)$ \\
\hline High-quality green development level & $(1.16,1.55)$ & $(1.24,1.39)$ & $(1.21,1.33)$ & $(1.24,1.50)$ & $(1.20,1.29)$ & $(1.12,1.30)$ \\
\hline
\end{tabular}

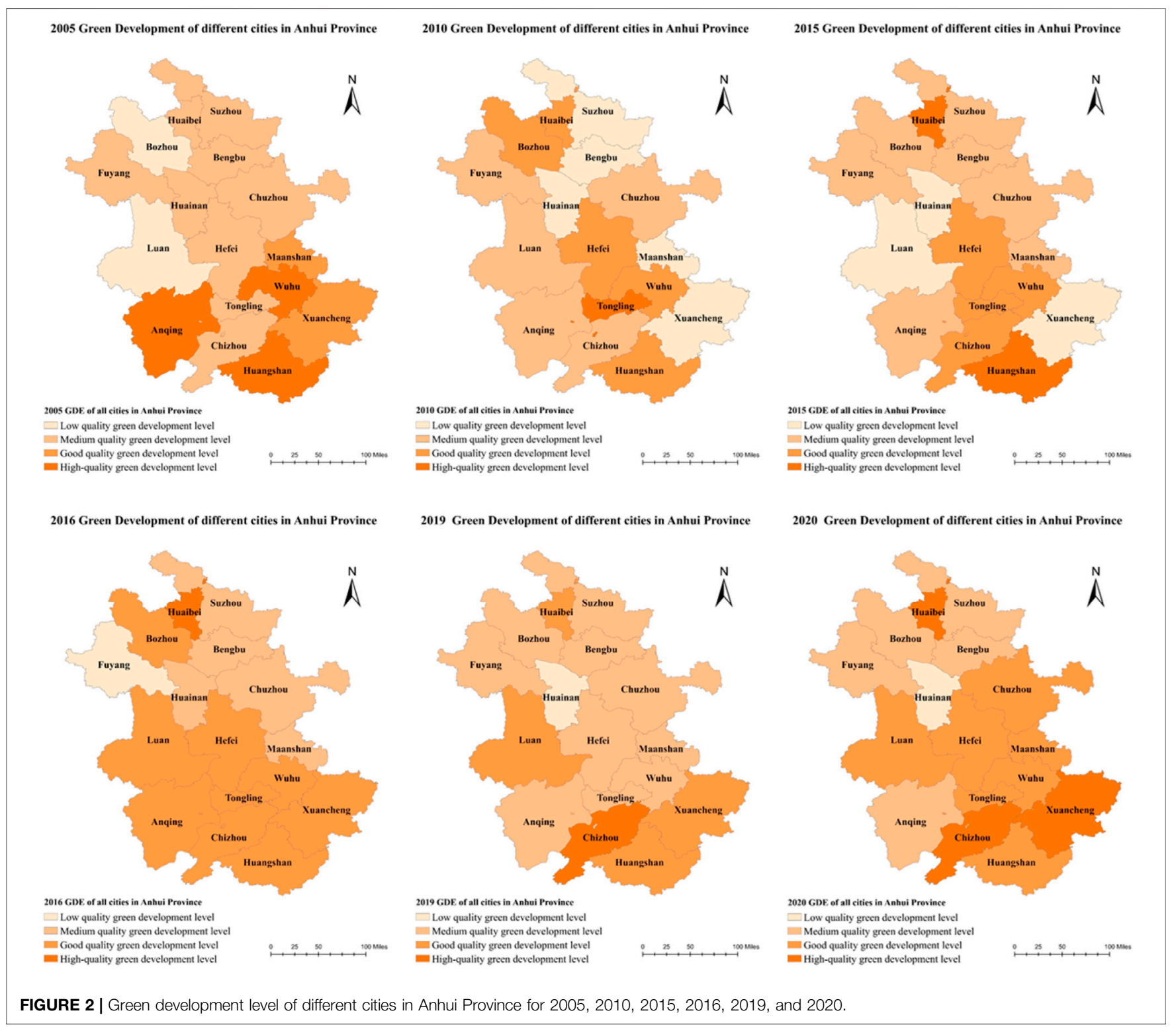

development level is high. Most cities showing an increasing level of green development over the 16 years and tend to be relatively stable.

Figure1 presents radar maps of green development efficiency for cities in Anhui Province from 2005 to 2020. Fluctuations in the green development level are greater from 2005 to 2011, which correspond to larger changes in the green development efficiency value for each city. This shows that at the beginning, the level of green development in various regions was very uneven, and there was no corresponding effective promotion and coordinated development. Conversely, from 2013 to 2019, the green development level is relatively stable, which is reflected in a lack of large fluctuations in the efficiency value. That is, after the year of green development, all regions actively adopt relevant strategies and development strategies. At the same time, relatively effective interaction is formed between various regions in Anhui 


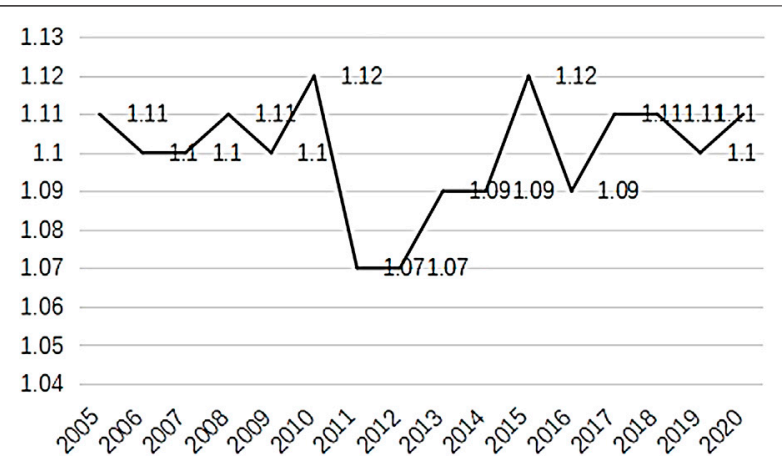

FIGURE 3 | Change in the mean green development efficiency in Anhui Province over the study period.

Province. The level of green development in all regions is small, and the regional development tends to be green and high-quality quantification.

Moreover, ArcGIS software was used to visualize the differentiation degree of the measured green development efficiency value. Six years $(2005,2010,2015,2016,2019$, and 2020) were selected to construct a differentiation map of green development efficiency for 16 cities in Anhui Province. According to the ArcGIS natural breakpoint method, the breakpoint interval of annual data is shown in Table 3.

Then, according to the natural segmentation point method in Table 3, the interval was obtained, and ArcGIS was used to reveal the green development level in the study area for the six different periods (Figure 2).

As can be seen from the differentiation charts of regional green development levels in different years, the distribution areas of high and low quality of regional green development in each year have great changes, and no city can always maintain the corresponding high or low level of green development. In general, the south of Anhui Province shows a relatively high efficiency and level of green development; most years were characterized by high-quality green development in the middle and southern parts of the study area. Thus, corresponding economic development in the middle and south of Anhui is attributed to the ecological concept of green development and circular development. However, the northern Anhui province has been located in the region with weak green development level, and its economic development level is relatively backward. However, it can be seen from the figure that the level of regional green development in northern Anhui has been improved. Furthermore, Huaibei city in northern Anhui has a relatively high level of green development, which is worth learning from other cities in northern Anhui. The northern Anhui should strengthen the development of regional green and further advance to the level of high quality green development.

Figure 3 shows the change in the arithmetic mean green development efficiency for all cities in Anhui Province over the study period. The mean green development efficiency is consistently greater than one, indicating a good green development level, and gradually increases from 2005 to 2010, then drops after 2010, before rising steadily from
2014, reaching a relatively stable trend of green development in recent years.

\section{Decomposition of Green Development Efficiency Using the GML Index}

The GML index with a global reference was used to measure the change of technology level in different periods. The totalfactor productivity was decomposed as follows:

$$
\begin{gathered}
\text { Total - factor productivity index (MI) } \\
=\text { technical efficiency index (EC) } \\
+ \text { technical progress index (TC) }
\end{gathered}
$$

According to Table 4, from 2005 to 2020, the overall total factor productivity and technological progress and technical efficiency index shows a rising trend, that green development level of the cities in Anhui province overall rose steadily, in Anhui province in the development of green technology innovation has increased, but the city's green management method. At the same time, it can be seen from the geometric average of the three efficiency values that the total factor productivity of green development efficiency in Anhui province increased by $3.05 \%$, the technical efficiency index increased by $0.6 \%$, and the technological progress index increased by $3.11 \%$ during the period from 2005 to 2020 , but the technical efficiency index developed relatively slowly. It shows that Anhui province should pay attention to the management and structural improvement of urban green development.

During the five years from 2011 to 2015, the total factor productivity was lower than 1 , and the total factor productivity showed a downward trend, accompanied by the decline of technological innovation index. In these years, the development of secondary and tertiary industries in Anhui province has led to the neglect of environmental governance and the emergence of environmental pollution problems. Starting from 2015, Anhui Province has paid great attention to the development of green economy, promoted the planning and construction of national new urbanization and vigorously promoted the construction of green development and ecological civilization. In other years, the total factor productivity showed a rising trend, and in 11 years, the total factor productivity showed a rising trend, showing a good development trend.

It can be seen from Figure 4 that the development trend line of total factor productivity of regional green development in Anhui province is consistent with the development trend of technological progress, which shows a synchronous change trend, indicating that technological progress is an important factor affecting regional green development. In the long run, the total factor productivity of regional green development has been rising steadily in the fluctuation, and the green total factor productivity is mostly above 1 . After the big fluctuation in 2014-2015, the total factor productivity of green development has been adjusted in time, which makes the total factor productivity of green development rise to a high level and tend to be stable. 
TABLE 4 | Decomposition of the green development efficiency by the GML index.

Total factor productivity(MI)

\begin{tabular}{lc} 
& Total factor product \\
\hline $2005-2006$ & 1.004296719 \\
$2006-2007$ & 1.036217158 \\
$2007-2008$ & 1.041494206 \\
$2008-2009$ & 0.869294308 \\
$2009-2010$ & 1.085759242 \\
$2010-2011$ & 1.143789592 \\
$2011-2012$ & 0.980472539 \\
$2012-2013$ & 0.974580918 \\
$2013-2014$ & 0.97193581 \\
$2014-2015$ & 0.857579456 \\
$2015-2016$ & 1.185765976 \\
$2016-2017$ & 1.102183436 \\
$2017-2018$ & 1.169587837 \\
$2018-2019$ & 1.058009414 \\
$2019-2020$ & 1.041952879 \\
Geometric mean & 1.030545062
\end{tabular}

)

$\begin{array}{cc}\begin{array}{c}\text { Technical } \\ \text { efficiency index(EC) }\end{array} & \begin{array}{c}\text { Technological } \\ \text { progress index(TC) }\end{array} \\ 1.029347559 & 0.976773223 \\ 0.955312143 & 1.09800415 \\ 1.042219928 & 1.01057228 \\ 0.946568015 & 0.924020795 \\ 1.072823515 & 1.033946074 \\ 0.957221013 & 1.199359243 \\ 0.999924994 & 0.990212288 \\ 1.026507266 & 0.951891004 \\ 1.021577058 & 0.968556234 \\ 1.042954148 & 0.825012239 \\ 0.977300426 & 1.208930611 \\ 1.027938326 & 1.087128367 \\ 0.997754056 & 1.181313393 \\ 0.989492369 & 1.06975099 \\ 1.018864237 & 1.019753754 \\ 1.006432881 & 1.031148804 \\ & \\ & \end{array}$

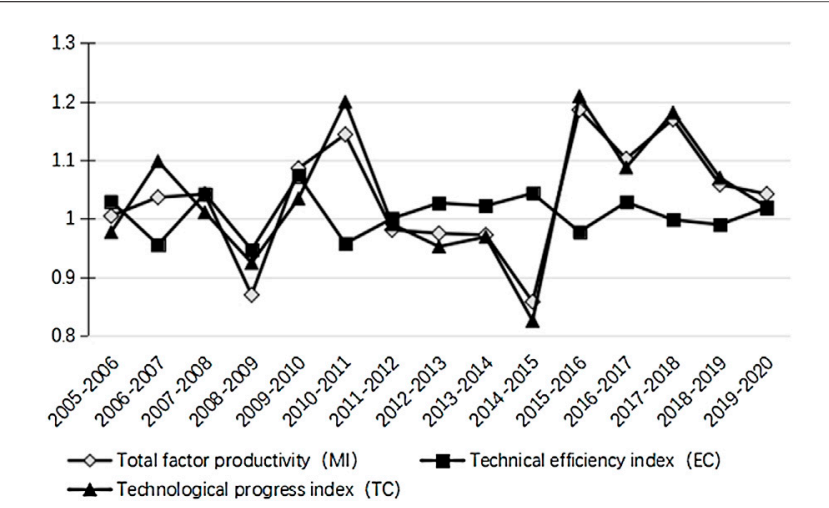

FIGURE 4 | Malmquist index decomposition trend chart of green development efficiency during the study period.

\section{EXPLORATORY SPATIAL DATA ANALYSIS OF REGIONAL GREEN DEVELOPMENT LEVEL}

\section{Global Moran's Index}

Spatial correlation analysis of the green development level was performed for 16 cities in Anhui Province from 2005 to 2020 using global and local Moran's indices. Prior to the spatial autocorrelation analysis, we constructed the inverse distance spatial matrix of each city. As the study area includes major cities in a single province, the distance between cities is relatively small, and their spatial distribution is relatively dense and compact; therefore, the inverse distance spatial matrix was deemed appropriate for the calculation:

$$
W= \begin{cases}1 / d_{i j} & d_{i j} \geq d \\ 0 & d_{i j}<d\end{cases}
$$

Here, $\mathrm{W}$ is the inverse distance weight matrix, and $\mathrm{d}_{\mathrm{ij}}$ is the distance between the spatial subjects in I and J, which is based
TABLE 5 | Global Moran's index.

\begin{tabular}{lcccc}
\hline & Variables & $\mathbf{I}$ & $\mathbf{z}$ & $\boldsymbol{p}$-value \\
\hline 2005 & GDE & $-0.111^{\star}$ & -0.356 & 0.072 \\
2006 & GDE & $-0.035^{\star}$ & 0.217 & 0.082 \\
2007 & GDE & $0.14^{\star \star}$ & 1.986 & 0.004 \\
2008 & GDE & $-0.029^{\star}$ & 0.379 & 0.070 \\
2009 & GDE & $0.005^{\star}$ & 0.616 & 0.053 \\
2010 & GDE & $-0.102^{\star}$ & -0.434 & 0.066 \\
2011 & GDE & $0.009^{\star \star}$ & 0.696 & 0.048 \\
2012 & GDE & $0.072^{\star \star}$ & 1.109 & 0.026 \\
2013 & GDE & $0.046^{\star \star}$ & 0.922 & 0.035 \\
2014 & GDE & $-0.224^{\star \star}$ & -1.394 & 0.016 \\
2015 & GDE & $0.019^{\star \star}$ & 0.732 & 0.046 \\
2016 & GDE & $0.031^{\star \star}$ & 0.85 & 0.039 \\
2017 & GDE & $0.139^{\star \star \star}$ & 2.567 & 0.001 \\
2018 & GDE & $0.027^{\star \star}$ & 0.802 & 0.042 \\
2019 & GDE & $0.13^{\star}$ & 0.499 & 0.061 \\
2020 & GDE & $0.012^{\star}$ & 0.653 & 0.051 \\
& & & &
\end{tabular}

on the above analysis of the green development level. The green development level is the main indicator, and the global Moran's index is calculated using STATA software.

According to Moran's I's test results (Table 5), spatial aggregation occurs among the green development levels of various cities in Anhui Province, and the spatial correlation fluctuates. Moreover, the spatial correlation of green development efficiency is relatively weak from 2005 to 2010, then becomes gradually stronger from 2010 . Except for a significant negative correlation in 2014, most years exhibit a positive spatial correlation, leading to spatial aggregation. Overall, both spatial correlation and aggregation of the regional green development efficiency are observed in Anhui Province, as well as a negative correlation in some years.

\section{Local Moran's Analysis}

Additionally, we calculated local Moran's scatter plots using STATA software to evaluate the spatial aggregation of green development efficiency in 16 cities of Anhui Province (Figure 5). Owing to space 


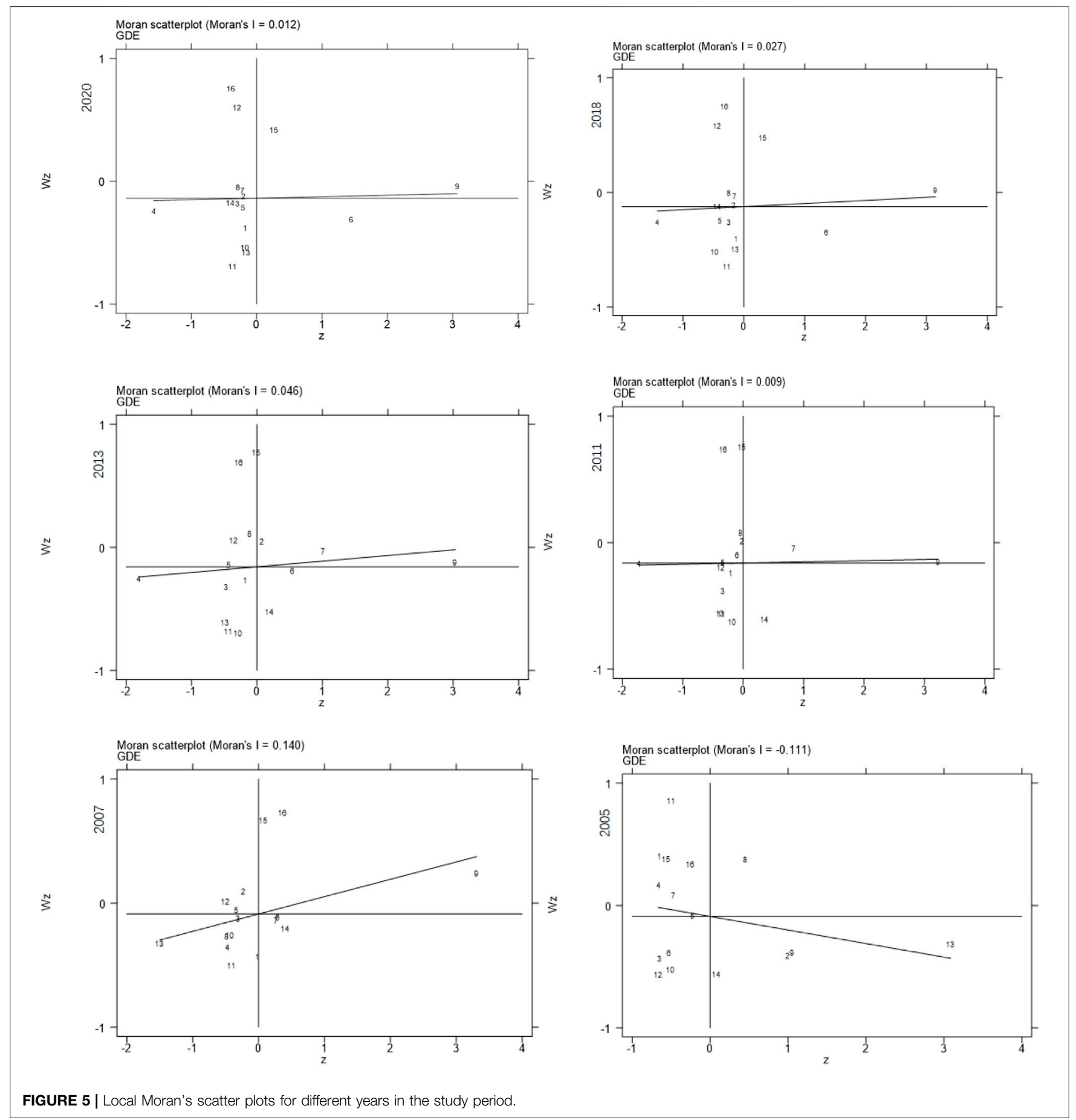

limitations, the scatter plots were only produced for specific years. The data are mainly distributed in the upper right, upper left and lower left quadrants, that is, they show high-low, low-high, and low-low aggregation. Generally, the results indicate relatively obvious spatial aggregation, which further indicates that the level of regional green development is positively correlated with the clustering distribution and exhibits spatial aggregation. A positive spatial correlation was observed in most years.

\section{FACTORS INFLUENCING DYNAMIC CHANGES IN GREEN DEVELOPMENT EFFICIENCY IN ANHUI PROVINCE}

\section{Spatial Econometric Model}

The spatial econometric model is a unique econometric model that can be used to discuss the spatial relationship between geographical economic units. According to the spatial 
TABLE 6 | Selection of factors influencing the efficiency of green development.

\begin{tabular}{|c|c|c|c|}
\hline Type of variable & Index & description & Symbol \\
\hline Explained variable & Level of green development & Green development level of regional economy & GDE \\
\hline \multirow[t]{8}{*}{ Explanatory variables } & Level of economic development & GDP per capita & GDP \\
\hline & Energy structure & Industrial electricity consumption/total electricity consumption in society & ES \\
\hline & Industrial structure & Output value of tertiary industry/output value of secondary industry & IS \\
\hline & Intensity of environmental governance & Comprehensive utilization rate of industrial waste and solids & ER \\
\hline & Digital economy & Number of broadband Internet access users & DIGE \\
\hline & Urbanization rate & Permanent population urbanization rate & UR \\
\hline & Degree of technological development & General public budget science and technology/GDP & TD \\
\hline & Opening to the outside world & Foreign direct investment & $\operatorname{lnOD}$ \\
\hline
\end{tabular}

correlation analysis described in Exploratory Spatial Data Analysis of Regional Green Development Level Section, the regional green development efficiency of Anhui Province is characterized by obvious spatial autocorrelation. Therefore, a spatial econometric model was constructed using the following formulas to comprehensively evaluate and analyze the green development efficiency of Anhui Province.

1) Spatial lag model (SAR):

$$
y_{i t}=\rho \sum_{j=1}^{n} \omega_{i j} y_{j r}+\beta x_{i t}+\mu_{i}+\lambda_{i}+\varepsilon_{i t}
$$

2) Spatial error model (SEM):

$$
\left\{\begin{array}{l}
y_{i t}=\beta x_{i t}+u_{t t}+\mu_{i}+\lambda_{i} \\
u_{t t}=\rho \sum_{j=1}^{n} \omega_{i j} u_{j t}+\varepsilon_{i t}
\end{array}\right.
$$

3) Spatial Durbin model (SDM):

$$
y_{i t}=\rho \sum_{j=1}^{n} \omega_{i j} y_{j t}+\beta x_{i t}+\theta \sum_{j=1}^{n} \omega_{i j} x_{j t}+\mu_{i}+\lambda_{i}+\varepsilon_{i t}
$$

In the above formulas, $y_{i t}$ represents the explained variable of the region $i$ in the period $t, x_{i t}$ represents the explanatory variable of the dimension $1 \times k, \omega_{i j}$ is the spatial weight matrix, $\varepsilon_{i t}$ and $u_{i t}$ represent the random error term, and $\mu_{i} \lambda_{i}$ represent the spatial effect and time effect, respectively. For the same reasons described in Exploratory Spatial Data Analysis of Regional Green Development Level Section, we used the inverse distance spatial matrix to construct the spatial econometric model.

\section{Influencing Factors and Research Hypothesis}

Calculations of the green development level should include multiple influencing factors. According to the results of previous studies and the availability of data, we evaluated the regional green development efficiency of Anhui Province from eight aspects (Table 6) with a view to determining ways of improving the level of green development. The green development efficiency (GDE) calculated from 2005 to 2020 for 16 cities in Anhui Province was employed as the explained variable. The explanatory variables were as follows.

\section{Level of Economic Development (GDP)}

A higher level of economic development can promote the gathering of talent, and the inward flow of talent can revitalize regional green development and improve the utilization efficiency of resources and energy. The per capita GDP after excluding the price factor was selected to represent the economic development level. Hypothesis H1: there is a positive correlation between the economic development level and green development efficiency.

\section{Energy Structure}

China's industrial energy consumption mainly depends on coal; however, no corresponding statistics on coal consumption exist for some prefecture-level cities in Anhui Province. We selected the ratio of industrial electricity consumption to total electricity consumption to measure the energy structure. Hypothesis $\mathrm{H} 2$ : there is a positive correlation between the energy structure and green development efficiency.

\section{Industrial Structure}

Generally, because of the development of secondary industry, secondary industry elements such as relative development require high energy consumption; therefore, secondary industry could inhibit the green development level. Moreover, the area of green development is mainly dependent on tertiary industry. Therefore, we selected the ratio of the tertiary industry output value to the secondary industry output value to represent the industrial structure. Hypothesis $\mathrm{H} 3$ : the industrial structure will effectively reduce the efficiency of urban green development.

\section{Environmental Governance}

The Porter hypothesis states that environmental management can stimulate businesses to invest in environmental technology, resulting in innovation that can offset the cost effects and enhance the level of development; thus, environmental regulation has an incentive effect on green development. However, according to the cost constraint theory, environmental regulation will increase the production cost of enterprises and affect the development of economic and technological efficiency. In this study, we used the comprehensive utilization rate of industrial waste and solids as a proxy variable for the environmental governance of businesses. 
TABLE 7 | Descriptive statistics of variables used in this study.

\begin{tabular}{lccccc}
\hline Variale & Obs & Mean & Std.Dev & Min & Max \\
\hline GDE & 256 & 1.112007 & 0.1662892 & 0.6086016 & 1.857068 \\
GDP & 256 & 3.372301 & 2.307842 & 0.376141 & 11.5623 \\
ES & 256 & 0.6531584 & 0.1463952 & 0.31 & 1.008338 \\
IS & 256 & 0.952676 & 0.393336 & 0.3213621 & 2.16689 \\
ER & 256 & 0.8870855 & 0.1121682 & 0.4007 & 1 \\
DIGE & 256 & 48.28035 & 53.48539 & 3 & 365 \\
UR & 256 & 0.5031922 & 0.1308707 & 0.238 & 0.794 \\
TD & 256 & 0.0041835 & 0.003663 & 0.0000839 & 0.0193759 \\
InOD & 256 & 10.30169 & 1.321967 & 6.304449 & 14.84543 \\
\hline
\end{tabular}

Hypothesis H4: environmental governance has an uncertain impact on green development efficiency.

\section{Development of the Digital Economy}

Development of the digital economy can effectively improve the efficiency of economic operation. Furthermore, the digital economy can generate information interaction, reduce resource waste, and improve the relative efficiency of resource allocation. Here, we selected the number of regional Internet users to measure the level of regional green development. Hypothesis H5: development of the digital economy will increase regional green development efficiency.

\section{Urbanization Level}

Relative development of the urbanization level indicates continuous development of the local economy and improved resource and energy utilization efficiency, which can increase the green development efficiency. The urbanization rate is expressed as the ratio of permanent urban residents to the total population. Hypothesis H6: there is a positive correlation between the urbanization level and green development efficiency.

\section{Degree of Scientific and Technological Development} Improvement of the scientific and technological level can improve the production mode and resource utilization efficiency of enterprises. Moreover, technological progress can promote the independent innovation of green production technology, thereby effectively improving the utilization degree of resources and further improving the utilization efficiency of resources. In this study, we measured the level of scientific and technological development using the ratio of science and technology expenditure to the GDP of each city in Anhui Province. Hypothesis H7: scientific and technological development has a positive effect on regional green development.

\section{Openness (InOD)}

According to the pollution haven hypothesis, foreign developed countries will transfer high-polluting and energy-consuming industries to developing countries, where the resulting environmental degradation will also increase the cost of pollution control in the region. However, the pollution halo hypothesis holds that opening to the outside world will attract and introduce foreign advanced technology, high-quality talent, and foreign direct investment, whereby the demand for green
TABLE 8 | Lagrange Multiplier test results.

\begin{tabular}{llcc}
\hline & Variable & Statistic & $\boldsymbol{p}$ Value \\
\hline LM test & - & - & - \\
Spatial error & & & \\
- & LM-lag & 3.674 & 0.055 \\
- & R-LM-lag & 5.282 & 0.022 \\
Spatial lag & & & \\
- & LM-error & $9.438^{\star \star \star}$ & 0.002 \\
- & R-LM-error & $11.046^{\star \star \star}$ & 0.001 \\
\hline & & &
\end{tabular}

products and fierce competition in the international market are conducive to improving green development efficiency. In this study, the utilization level of foreign capital is represented by the actual utilized foreign direct investment in each city, which is treated logarithmically. Hypothesis H8: the degree of openness has an uncertain effect on the efficiency of urban green development.

\section{Empirical Results of the Spatial Econometric Model}

Based on the eight selected indicators, we empirically analyzed the economic data of 16 urban areas in Anhui Province over the past 16 years. Descriptive statistics of the variables used in this study are shown in Table 7 .

\section{Model Selection}

In the spatial econometric model, ordinary least squares regression was first adopted, and the Lagrange Multiplier test was then performed on the regression results in order to determine whether the model exhibited spatial error or spatial lag (Table 8). The test results of the spatial error model and the robust spatial error model were not significant. However, the two test methods of the spatial lag model passed the significance level of 0.01 , indicating that the general panel regression exhibited a spatial lag effect. As the significance of the two spatial lag test methods was significantly higher than that of the spatial error model, the spatial lag model was initially constructed.

The preliminary regression results of the three models are shown in Table 9. The spatial lag model exhibited the highest $\mathrm{R}$ squared value. According to the Akechi information criterion scores for SAR $(-7.727,31.270)$, SEM $(-14.239,24.758)$, and $\operatorname{SDM}(-39.613,31.291)$, the SAR model was selected as the optimal model. Then, Hausman's test was conducted to determine whether random or fixed effects should be used. The test value was positive (25.68) and the significance level was 0.0042 , indicating that the fixed effects model should be selected. We also tested the optimality of regional fixed effects, time fixed effects, and double fixed effects. According to the $\mathrm{R}$ squared value, the most suitable model was the spatial Durbin model with time fixed effects (Table 10).

\section{Final Model Regression Results}

The form of the optimal model, i.e., the SAR model with fixed time effects, is as follows: 
TABLE 9 | Model preliminary regression results.

\begin{tabular}{|c|c|c|c|c|c|c|c|}
\hline & SAR & SEM & SDM & - & SAR & SEM & SDM \\
\hline \multirow[t]{2}{*}{ GDP } & $0.122^{\star \star \star}$ & $0.127^{\star \star \star}$ & $0.114^{\star \star \star}$ & $W x$ & - & - & - \\
\hline & (6.73) & (7.06) & (5.53) & GDP & - & - & 0.004 \\
\hline \multirow[t]{2}{*}{ ES } & $-0.963^{\star \star \star}$ & $-1.003^{\star \star \star}$ & $-0.680^{\star \star \star}$ & & - & - & $(0.04)$ \\
\hline & $(-5.99)$ & $(-6.06)$ & $(-3.14)$ & ES & - & - & $2.466^{\star}$ \\
\hline \multirow[t]{2}{*}{ IS } & $0.259^{\star \star \star \star}$ & $0.279^{\star \star \star}$ & $0.334^{\star \star \star}$ & & - & - & $(1.78)$ \\
\hline & (4.32) & $(4.45)$ & $(4.58)$ & IS & - & - & $1.159^{\star \star \star}$ \\
\hline \multirow[t]{2}{*}{ ER } & -0.001 & $-0.003^{\star}$ & $-0.005^{\star \star \star}$ & - & - & - & $(2.74)$ \\
\hline & $(-0.83)$ & $(-1.66)$ & $(-2.74)$ & ER & - & - & $-0.013^{\star}$ \\
\hline \multirow[t]{2}{*}{ DIGE } & $0.004^{\star \star \star}$ & $0.004^{\star \star \star}$ & $0.004^{\star \star \star}$ & - & - & - & $(-1.76)$ \\
\hline & (7.84) & (8.21) & (7.58) & DIGE & - & - & $-0.007^{\star \star}$ \\
\hline \multirow[t]{2}{*}{ UR } & $0.004^{\star \star}$ & 0.003 & -0.002 & - & - & - & $(-2.21)$ \\
\hline & (2.03) & $(1.48)$ & $(-0.70)$ & UR & - & - & $-0.034^{\star \star \star}$ \\
\hline \multirow[t]{2}{*}{ TD } & 1.554 & 6.032 & 5.686 & - & - & - & $(-2.75)$ \\
\hline & $(0.23)$ & (0.83) & $(0.74)$ & TD & - & - & 14.487 \\
\hline \multirow[t]{2}{*}{ InOD } & $-0.052^{\star \star}$ & -0.039 & 0.026 & - & - & - & $(0.44)$ \\
\hline & $(-2.18)$ & $(-1.61)$ & (0.89) & $\operatorname{lnOD}$ & - & - & $0.294^{\star \star}$ \\
\hline Spatial & - & - & - & - & - & - & (2.26) \\
\hline \multirow[t]{2}{*}{ rho } & $-0.510^{\star \star \star}$ & - & $-0.585^{\star \star \star}$ & r2 & 0.298 & 0.234 & 0.277 \\
\hline & $(-2.66)$ & - & $(-2.84)$ & aic & -7.727 & -14.239 & -39.613 \\
\hline \multirow[t]{2}{*}{ lambda } & - & $-0.780^{\star \star \star}$ & - & bic & 31.270 & 24.758 & 31.291 \\
\hline & - & $(-3.75)$ & - & $\mathrm{N}$ & 256.000 & 256.000 & 256.000 \\
\hline \multicolumn{8}{|l|}{ Variance } \\
\hline \multirow[t]{2}{*}{ sigma2_e } & $0.051^{\star \star \star}$ & $0.048^{\star \star *}$ & $0.042^{\star \star \star}$ & - & - & - & - \\
\hline & (11.10) & (10.80) & (10.97) & - & - & - & - \\
\hline
\end{tabular}

TABLE $\mathbf{1 0}$ | Mode I selection results.

\begin{tabular}{cccc}
\hline & Ind & Time & Both \\
\hline Main & & & \\
GDP & 0.007 & $0.122^{\star \star \star}$ & 0.003 \\
& $(0.56)$ & $(6.73)$ & $(0.16)$ \\
ES & 0.195 & $-0.963^{\star \star \star}$ & 0.192 \\
& $(1.06)$ & $(-5.99)$ & $(0.99)$ \\
IS & $0.112^{\star \star}$ & $0.259^{\star \star \star}$ & $0.155^{\star \star \star}$ \\
& $(2.34)$ & $(4.32)$ & $(2.72)$ \\
ER & $-0.002^{\star}$ & -0.001 & $-0.002^{\star}$ \\
DIGE & $(-1.83)$ & $(-0.83)$ & $(-1.91)$ \\
& $0.001^{\star \star}$ & $0.004^{\star \star \star}$ & $0.001^{\star \star}$ \\
UR & $(2.41)$ & $(7.84)$ & $(2.15)$ \\
& $0.011^{\star \star}$ & $0.004^{\star \star}$ & $0.010^{\star \star \star}$ \\
TD & $(4.51)$ & $(2.03)$ & $(4.37)$ \\
InOD & 9.356 & 1.554 & $12.514^{\star \star}$ \\
& $(1.55)$ & $(0.23)$ & $(2.06)$ \\
Spatial & -0.001 & $-0.052^{\star \star}$ & 0.006 \\
rho & $(-0.08)$ & $(-2.18)$ & $(0.30)$ \\
& & & \\
Variance & -0.016 & $-0.510^{\star \star \star}$ & $-0.507^{\star \star \star}$ \\
sigma2_e & $(-0.18)$ & $(-2.66)$ & $(-2.67)$ \\
& & & \\
r2 & $0.020^{\star \star *}$ & $0.051^{\star \star \star}$ & $0.018^{\star \star \star}$ \\
& $(11.31)$ & $(11.10)$ & $(11.11)$ \\
& 0.002 & 0.298 & 0.003
\end{tabular}

$$
\begin{aligned}
G D E_{i t}= & \rho \sum_{j=1}^{N} \omega_{i j} G D E_{i t}+a_{0}+\beta_{1} G D P_{i t}+\beta_{2} E S_{i t}+\beta_{3} I S_{i t}+\beta_{4} E R_{i t} \\
& +\beta_{5} D I G E_{i t}+\beta_{6} U R_{i t}+\beta_{7} T D_{i t}+\beta_{8} G S_{i t}+\beta_{9} L n O D_{i t} \\
& +\mu_{i}+\lambda_{i}+\varepsilon_{i t}
\end{aligned}
$$

where $i, j=1,2, \ldots, N ; t=1,2, \ldots, T$. The final model regression results are shown in Table 11. The regression results and corresponding regression coefficients calculated by STATA indicate the factors affecting green development of the regional economy in Anhui Province.

1) The economic benefit index has a positive effect on the regional green development efficiency, with a significance level of $1 \%$, which verifies hypothesis 1 . Thus, each unit increase in per capita GDP will increase the regional green development level by 0.122 units, indicating the importance of economic benefits to regional green development.

2) The energy structure has a significant negative impact on regional economic development, inhibiting the regional green development efficiency of each city in Anhui Province. This verifies hypothesis 2 .

3) The industrial structure has a significant positive impact on regional green development, which verifies hypothesis 3 . Specifically, higher development of tertiary industry compared with secondary industry has a corresponding positive impact on regional economic development, which indicates the importance of a rational distribution of the industrial structure and an appropriate increase in tertiary industry development.

4) The intensity of environmental governance has a negative but not significant impact on regional green development efficiency. This proves the Porter hypothesis and indicates that the impact of environmental regulation on green development efficiency has not reached the Porter inflection point, that is, the impact of environmental management intensity on regional green development efficiency has not transformed from the negative effect of 
TABLE 11 | Final regression results of the spatial lag model.

\begin{tabular}{|c|c|c|c|c|c|c|}
\hline GDE & Coefficient & Std. Error & $\mathbf{z}$ & $P>z$ & 95\% Conf & Interval \\
\hline GDP & $0.122^{\star \star \star}$ & 0.018 & 6.730 & 0.000 & 0.087 & 0.158 \\
\hline ES & $-0.963^{\star \star \star}$ & 0.161 & -5.990 & 0.000 & -1.278 & -0.648 \\
\hline IS & $0.259^{\star \star \star}$ & 0.060 & 4.320 & 0.000 & 0.142 & 0.376 \\
\hline ER & -0.00119 & 0.001 & -0.830 & 0.405 & -0.004 & 0.002 \\
\hline DIGE & $0.00364^{\star \star \star}$ & 0.000 & 7.840 & 0.000 & 0.005 & 0.003 \\
\hline UR & $0.00414^{\star \star}$ & 0.002 & 2.030 & 0.043 & 0.000 & 0.008 \\
\hline TD & 1.554 & 6.729 & 0.230 & 0.817 & 14.742 & 11.635 \\
\hline InOD & $-0.0520^{\star \star}$ & 0.024 & -2.180 & 0.029 & -0.099 & -0.005 \\
\hline rho & -0.510 & 0.192 & -2.660 & 0.008 & -0.887 & -0.134 \\
\hline sigma2_e & 0.051 & 0.005 & 11.100 & 0.000 & 0.042 & 0.060 \\
\hline
\end{tabular}

"cost of compliance" to the positive effect of "innovation compensation." Specifically, the "compensation effect" of environmental management has not offset the "cost effect."

5) Development of the digital economy has a significant positive impact on regional green development efficiency, which verifies hypothesis 5 . That is, a digital economy driven by data and informatization can effectively promote information exchange and interworking, and improve the level of regional green development.

6) An increase in the regional urbanization level has a positive and significant effect on regional green development, which verifies hypothesis 6 .

7) Scientific and technological development has a positive impact on regional green development, but does not pass the significance test, which negates hypothesis 6 . This result suggests that the regional development of science and technology may be caused by enterprises strengthening research and development into profit-oriented production technology, whereby businesses blindly pursue economic benefits and invest less in research and development into clean technology. This with Qiu Zhaolin and Wang Yehui conclusion is the same, technology research and development can improve the ecological efficiency, but at present, around the core technology research and development of Anhui level is not high, and the enterprise research and development tend to be more productive technology research and development of the scale expansion, ignoring the clean and environmentally friendly production technology research and development. The reason may be that enterprises tend to strengthen the research and development of profit-oriented production technology, that is, they blindly pursue economic benefits and invest less in the research and development of clean technology. At the same time, it may be that the technology market in Anhui province develops late, the transaction volume is small, and it is not effective to promote the progress and diffusion of regional green development efficiency. It still needs time to develop, and it cannot significantly improve the operation efficiency of regional system. Investment in science and technology has not significantly improved the efficiency of green development.

8) The level of opening up has a significant negative effect on regional green economic development. This confirms the pollution haven hypothesis, in which attracting foreign
TABLE 12 | Decomposition of spatial spillover effects.

\begin{tabular}{lccc}
\hline Variables & LR_Direct & LR_Indirect & LR_Total \\
\hline GDP & $0.126^{\star \star \star}$ & $-0.0429^{\star \star \star}$ & $0.0832^{\star \star \star}$ \\
& $(0.0194)$ & $(0.0151)$ & $(0.0163)$ \\
ES & $-0.995^{\star \star \star}$ & $0.335^{\star \star \star}$ & $-0.659^{\star \star \star}$ \\
& $(0.158)$ & $(0.112)$ & $(0.148)$ \\
IS & $0.270^{\star \star \star}$ & $-0.0923^{\star \star}$ & $0.178^{\star \star \star}$ \\
& $(0.0597)$ & $(0.0369)$ & $(0.0442)$ \\
ER & -0.00125 & 0.000424 & -0.000823 \\
& $(0.00141)$ & $(0.000524)$ & $(0.000939)$ \\
DIGE & $0.00375^{\star \star \star}$ & $0.00127^{\star \star \star}$ & $0.00502^{\star \star \star}$ \\
& $(0.000460)$ & $(0.000423)$ & $(0.000460)$ \\
UR & $0.00436^{* \star}$ & $-0.00145^{\star}$ & $0.00291^{\star}$ \\
& $(0.00206)$ & $(0.000808)$ & $(0.00151)$ \\
TD & 1.816 & 0.642 & 2.458 \\
& $(6.871)$ & $(2.486)$ & $(4.514)$ \\
InOD & $-0.0522^{* \star}$ & $0.0175^{\star}$ & $-0.0347^{\star \star}$ \\
& $(0.0229)$ & $(0.00949)$ & $(0.0162)$ \\
Observations & 256 & 256 & 256 \\
R-squared & 0.298 & 0.298 & 0.298
\end{tabular}

capital reduces the need for green development, and the introduction of multinational enterprises leads to pollution within the region. Thus opening up brings a heavy environmental burden to the local area and inhibits the efficiency of regional green development.

\section{Decomposition of Spatial Spillover Effects}

The effects of different influencing factors were decomposed into direct effects and brief effects (Table 12). The economic benefits of per capita GDP growth include the green development of local regional economy, and the significant positive impact on local regional economic development has a positive impact on the level of green development. However, due to the relative imbalance of inter-regional development, there will be a "siphon effect" that makes the surrounding resources flow to the cities and regions with superior development, which will also have a negative impact on the surrounding areas. Economic elements and resource elements always flow to more developed cities and regions, which leads to a corresponding competition effect with neighboring cities. Thus, a relative improvement in the local economic development level will have adverse effects on neighboring cities. Although the energy structure has an adverse effect on local green development, it will generate a positive 
spillover effect in neighboring cities. This is attributed to environmental pollution caused by industrial energy consumption and relatively low energy utilization efficiency in the city; however, this can lead to outflow of the urban population and talent to neighboring cities. According to the significance test, adjustment of the industrial structure can lead to a positive impact on the regional green development level but produce significant negative spillover effects. That is, adjustment of the industrial structure may occur through the transfer of highly polluting enterprises to surrounding cities, resulting in a decline in their green development level. Thus, the industrial structure of Anhui Province has not yet achieved complementary advantages and coordinated development between urban areas.

Development of the digital economy plays a positive role in promoting development of the local green economy, but also has significant spillover effects, indicating synergistic development and effective information exchange between various urban areas in Anhui Province. An increase in the local urbanization level can promote green economic development; however, surrounding areas will experience negative spillover effects because outflow of the local population will have an adverse influence on the green development level. Although the direct effect of opening up to the outside world is negative, the spatial spillover effect is positive. That is, increased opening up to the outside world may compete with local industry and have a negative impact on local economic development. However, according to the "pollution haven" hypothesis, the arrival of foreign high-polluting industry leads to a local brain drain, a local increase of pollution-intensive industry, and deterioration of the ecological environment, which may "crowd out" development of provincial innovation factors, leading to a high-tech brain drain at the provincial level. Finally, the influence of scientific and technical development and environmental governance is not significant. This may be because of a substantial difference in environmental governance intensity and technological development level between cities in Anhui Province; thus, the combined spatial effect was not significant.

\section{CONCLUSIONS AND RECOMMENDATIONS}

In this study, we used panel data for 16 prefecture-level cities in Anhui Province from 2005 to 2020 and the super-SBM model to measure the green development efficiency of Anhui Province. The global Malmquist Index was used to analyze dynamic changes in the green development efficiency and establish a corresponding spatial lag model. The modeling results revealed the influencing factors and spillover effects of green development efficiency in Anhui Province, from which we drew the following conclusions.

The overall green development efficiency of all urban areas in Anhui Province showed a fluctuating trend, with most cities exhibiting medium of higher green development efficiency. According to spatial correlation analysis of the green development level in Anhui Province, various cities exhibited spatial aggregation, with high, high, and low values of green development efficiency. Among the factors influencing the level of green development, economic development, the industrial structure, digital economy development, and the urbanization level showed relatively significant positive correlations with the regional economic development level, whereas the energy structure and level of opening up showed a significant negative correlation with the regional green development efficiency. The influence of environment management and scientific and technological development was not significant. Regarding the various spatial spillover effects, economic efficiency, the industrial structure, and the urbanization rate showed positive effects on local green development but negative spillover effects on surrounding areas, whereas the energy structure, relative economic development, and level of opening up produced positive spillover effects.

Based on these findings, we propose the following recommendations for improving regional green development in Anhui Province. First, the level of regional economic development needs to be improved accordingly. The green development of regional economy cannot be separated from the high-quality development of regional economy, and the development of regional economy cannot be separated from the support of the government, government functions should be fully developed to achieve win-win economic, social, and environmental benefits. Efforts should be stepped up to promote green development, eliminate low-quality enterprises, improve laws and regulations on environmental protection, and resolutely implement the green development strategy. Second, we should strengthen regional cooperation and exchanges, promote digital economy interaction to establish a solid communication mechanism, strengthen project exchange and joint innovation, and speed up cooperation in resource development, environmental governance, industrial docking, and other areas. Third, the adjustment of the energy mix and industrial structure is also crucial, it is important to accelerate rational adjustment of industrial and energy structures. This includes reasonably adjusting the relative development degree of tertiary and secondary industries and transforming and upgrading the industrial structure to improve the efficiency of green development. green transformation of small- and mediumsized enterprises should be promoted, and advanced manufacturing and new energy industries should be vigorously developed. Meanwhile, the government needs to strengthen the green supervision of enterprises in the region and carry out effective environmental supervision. The urbanization level of the region also plays an important role in promoting the green development of the region. Fourth, we propose improving the utilization of foreign investment structure. Specifically, we should attach importance to the quality of foreign investment, and avoid turning local areas into a foreign "pollution refuge." We should also strengthen the standards for introducing foreign enterprises, and implement corresponding supervision and strict regulation of the environmental governance of foreign enterprises. Fifth, it is important to increase the input of green scientific and technological innovation. This can be achieved through increased government support for independent innovation, acknowledging that scientific and technological input is an 
important driving force for regional green development. Due to the relative regional limitations of this study as well as the relative limitations of research methods and data, more indepth studies are needed in the future to further discuss and deeply study the level of regional green development.

\section{DATA AVAILABILITY STATEMENT}

The original contributions presented in the study are included in the article/Supplementary material, further inquiries can be directed to the corresponding author.

\section{REFERENCES}

Acemoglu, D., Aghion, P., Bursztyn, L., and Hemous, D. (2012). The Environment and Directed Technical Change. Am. Econ. Rev. 102 (1), 131-166. doi:10.1257/ aer.102.1.131

Burnett, J. W., Bergstrom, J. C., and Dorfman, J. H. (2013). A Spatial Panel Data Approach to Estimating U.S. State-Level Energy Emissions. Energ. Econ. 40, 396-404. doi:10.1016/j.eneco.2013.07.021

Che, L., Bai, Y., Zhou, L., Wang, F., Ji, X., and Qiao, F. (2018). Spatial Characteristics and Spillover Analysis of green Development Efficiency in China. Scientia Geographica Sinica 38 (11), 1788-1798. doi:10.13249/j.cnki. sgs.2018.11.006

Chen, C. (2016). China's Industrial green Total Factor Productivity and its Determinants-An Empirical Study Based on Ml index and Dynamic Panel Data Model. Stat. Res. 33 (3), 53-62.

Feng, C., Wang, M., Liu, G.-C., and Huang, J.-B. (2017). Green Development Performance and its Influencing Factors: A Global Perspective. J. Clean. Prod. 144, 323-333. doi:10.1016/j.jclepro.2017.01.005

Guo, Y., Zeng, Z., Tian, J., Xu, F., Chen, L., and Zhou, A. (2017). Uncovering the Strategies of green Development in a Chinese Province Driven by Reallocating the Emission Caps of Multiple Pollutants Among Industries. Sci. Total Environ. 607-608, 1487-1496. doi:10.1016/j.scitotenv.2017.06.234

Hille, E., Lambernd, B., and Tiwari, A. K. (2021). Any Signs of Green Growth? A Spatial Panel Analysis of Regional Air Pollution in South Korea. Environ. Resource Econ. 80 (4), 719-760. doi:10.1007/s10640-021-00607-4

Huang, Y., and Lin, L. (2017). A Comprehensive Assessment of green Development and its Spatial-Temporal Evolution in Urban Agglomerations of china. Geographical Res. 36 (7), 1309-1322. doi:10. 11821/dlyj201707010

Li, W., Liu, Y., Zhang, X., and Deng, C. (2019). Spatial-temporal Evolution of Urban green Development Level and its Obstacle Factors in Shaanxi Province. Res. Soil Water Conservation 26 (6), 280-289.

Li, Y., Chen, Y., and Li, Q. (2020). Assessment Analysis of green Development Level Based on S-type Cloud Model of Beijing-TianjinHebei, china. Renew. Sustain. Energ. Rev. 133, 110245. doi:10.1016/j.rser. 2020.110245

Liu, C., Gao, X., Ma, W., and Chen, X. (2019). Research on Regional Differences and Influencing Factors of green Technology Innovation Efficiency of china's High-Tech Industry. J. Comput. Appl. Maths. 369, 112597. doi:10.1016/j.cam.2019.112597

Liu, D., Zhu, X., and Wang, Y. (2020). China's Agricultural green Total Factor Productivity Based on Carbon Emission: an Analysis of Evolution Trend and Influencing Factors. J. Clean. Prod. 278 (1), 123692. doi:10.1016/j.jclepro.2020. 123692

Lozano, S., and Gutiérrez, E. (2011). Slacks-based Measure of Efficiency of Airports with Airplanes Delays as Undesirable Outputs. Comput. Operations Res. 38 (1), 131-139. doi:10.1016/j.cor.2010.04.007

Merino-Saum, A., Clement, J., Wyss, R., and Baldi, M. G. (2020). Unpacking the Green Economy Concept: A Quantitative Analysis of 140 Definitions. J. Clean. Prod. 242, 118339. doi:10.1016/j.jclepro.2019.118339

\section{AUTHOR CONTRIBUTIONS}

XC: Writing-original draft, Supervision. WW: Conceptualization, Methodology, Writing-review and editing. AR: Project administration, Software. SR: Resources, Funding acquisition. XZ: Formal analysis, Investigation, Validation.

\section{FUNDING}

This work was supported by the Anhui Province Innovation Development Research Project (Grant No. 2021CX053).

Peng, X. (2020). Strategic Interaction of Environmental Regulation and green Productivity Growth in china: green Innovation or Pollution Refuge? Sci. Total Environ. 732, 139200. doi:10.1016/j.scitotenv.2020.139200

Reinhard, S., Knox Lovell, C. A., and Thijssen, G. J. (2000). Environmental Efficiency with Multiple Environmentally Detrimental Variables; Estimated with SFA and DEA. Eur. J. Oper. Res. 121 (2), 287-303. doi:10.1016/s0377-2217(99)00218-0

Shahzad, U., Schneider, N., and Ben Jebli, M. (2021). How Coal and Geothermal Energies Interact with Industrial Development and Carbon Emissions? an Autoregressive Distributed Lags Approach to the Philippines. Resour. Pol. 74, 102342. doi:10.1016/j.resourpol.2021. 102342

Shahzad, U., Ferraz, D., Nguyen, H.-H., and Cui, L. (2022). Investigating the Spill Overs and Connectedness between Financial Globalization, HighTech Industries and Environmental Footprints: Fresh Evidence in Context of China. Technol. Forecast. Soc. Change 174, 121205. doi:10.1016/j. techfore.2021.121205

Si, L., Wang, J., Yang, S., Yang, Y., and Zhang, J. (2021). Urban Green Development towards Sustainability in Northwest China: Efficiency Assessment, Spatial-Temporal Differentiation Characters, and Influencing Factors. Complexity 2021, 19. doi:10.1155/2021/6630904

Song, M., Peng, L., Shang, Y., and Zhao, X. (2022). Green Technology Progress and Total Factor Productivity of Resource-Based Enterprises: A Perspective of Technical Compensation of Environmental Regulation. Technol. Forecast. Soc. Change 174, 121276. doi:10.1016/j.techfore.2021. 121276

Sun, H., Edziah, B. K., Kporsu, A. K., Sarkodie, S. A., and Taghizadeh-Hesary, F. (2021a). Energy Efficiency: The Role of Technological Innovation and Knowledge Spillover. Technol. Forecast. Soc. Change 167, 120659. doi:10. 1016/j.techfore.2021.120659

Sun, H., Edziah, B. K., Sun, C., and Kporsu, A. K. (2021b). Institutional Quality and its Spatial Spillover Effects on Energy Efficiency. Socio-Economic Plann. Sci., 1. 101023. doi:10.1016/j.seps.2021.101023

Tian, Y., and Liu, X. (2021). Evaluation of Regional green Development Efficiency Based on Super-efficiency SMBM-DEA and Spatial Analysis. Stat. Inf. Forum 36 (8), 56-65. doi:10.3969/j.issn.1007-3116.2021.08.006

Wang, X., and Li, Y. (2020). Research on Measurement and Improvement Path of Industrial green Development in China: a Perspective of Environmental Welfare Efficiency. Environ. Sci. Pollut. Res. 27 (34), 42738-42749. doi:10.1007/s11356-02009979-4

Wu, D., Wang, Y., and Qian, W. (2020). Efficiency Evaluation and Dynamic Evolution of China's Regional green Economy: A Method Based on the Super-PEBM Model and DEA Window Analysis. J. Clean. Prod. 264, 121630. doi:10.1016/j.jclepro.2020.121630

Xia, W., Apergis, N., Bashir, M. F., Ghosh, S., Doğan, B., and Shahzad, U. (2022). Investigating the Role of Globalization, and Energy Consumption for Environmental Externalities: Empirical Evidence from Developed and Developing Economies. Renew. Energ. 183, 219-228. doi:10.1016/j.renene. 2021.10.084

Yuan, H., Feng, Y., Lee, J., Liu, H., and Li, R. (2020). The Spatial Threshold Effect and its Regional Boundary of Financial Agglomeration on green 
Development: A Case Study in China. J. Clean. Prod. 244, 118670. doi:10. 1016/j.jclepro.2019.118670

Zhao, X., Ma, X., Chen, B., Shang, Y., and Song, M. (2022). Challenges toward Carbon Neutrality in China: Strategies and Countermeasures. Resour. Conservation Recycling 176, 105959. doi:10.1016/j.resconrec.2021.105959

Zhou, L., Zhou, C., Che, L., and Wang, B. (2020). Spatio-temporal Evolution and Influencing Factors of Urban green Development Efficiency in china. J. Geogr. Sci. 30 (5), 724-742. doi:10.1007/s11442-020-1752-5

Conflict of Interest: The authors declare that the research was conducted in the absence of any commercial or financial relationships that could be construed as a potential conflict of interest.
Publisher's Note: All claims expressed in this article are solely those of the authors and do not necessarily represent those of their affiliated organizations, or those of the publisher, the editors and the reviewers. Any product that may be evaluated in this article, or claim that may be made by its manufacturer, is not guaranteed or endorsed by the publisher.

Copyright (c) 2022 Cai, Wang, Rao, Rahim and Zhao. This is an open-access article distributed under the terms of the Creative Commons Attribution License (CC BY). The use, distribution or reproduction in other forums is permitted, provided the original author(s) and the copyright owner(s) are credited and that the original publication in this journal is cited, in accordance with accepted academic practice. No use, distribution or reproduction is permitted which does not comply with these terms. 